\title{
A EVOLUÇÃO DA AGRICULTURA E O IMPACTO GERADO PELOS PROCESSOS DE INOVAÇÃO: UM ESTUDO DE CASO NO MUNICÍPIO DE COXILHA-RS
}

\author{
Eluane Parizotto Seidler \\ Pós-Graduanda no MBA em Administração de Agronegócios e Biotecnologia na UNINTER \\ Endereço para contato: Rio do Peixe, RS 463, Interior - Coxilha/RS \\ CEP: 99145-000 - E-mail: eluanepseidler@gmail.com
}

\section{Luiz Fernando Fritz Filho}

Professor Permanente no Mestrado em Administração da Universidade de Passo Fundo (UPF)

Endereço para contato: Universidade de Passo Fundo, BR 285, São José - Passo Fundo/RS

CEP: 99052-900- E-mail: fritz@upf.br

Recebido em 01 de março de 2016. Aceito em 29 de agosto de 2016.

\section{RESUMO}

A agricultura brasileira tem papel importante na economia do país e sofre evolução constante, notadamente a partir do processo conhecido como "modernização da agricultura". Acredita-se que o significativo crescimento da produtividade das culturas agrícolas tenha forte correlação com os avanços tecnológicos. Nessa perspectiva, este artigo analisa qual o impacto gerado pela inovação, pela tecnologia e por formas de gestão durante a trajetória de uma unidade de produção agrícola localizada no Estado do RS, no município de Coxilha, por meio da compreensão dos sistemas produtivos pelos quais a unidade investigada passou. $\mathrm{O}$ estudo pauta-se nos modelos de análise das trajetórias de unidades de produção agrícola desenvolvidos por Fritz Filho (2009), agregados de variáveis ligadas, sobretudo, à inovação. A investigação incorporou elementos derivados de estudos de Oslo (2013); Saenz e García Capote (2002); Santos e Sanchez (2014); e, Schumpeter (1988). Como resultados, destaca-se a inovação tecnológica em processos, produtos e formas de gestão, que permitiu aumentar a produção e a qualidade nos produtos e, também, ampliar a renda e a qualidade de vida, passando a gestão a ser mais profissionalizada. Adicionalmente, o estudo apontou o uso de crédito rural do Estado como importante para a trajetória da unidade investigada.

Palavras-chave: Inovação tecnológica; Sistemas de produção; Trajetórias.

\begin{abstract}
Brazilian agriculture has an important role in the economy and suffers constant evolution, notably from the process known as "modernization of agriculture". It is believed that the significant growth of productivity of agricultural crops has strong correlation with the technological advances. In this perspective, this paper analyzes the impact generated by innovation, technology and management methods during the course of an agricultural production unit in the state of Rio Grande do Sul, in the municipality of Coxilha, through understanding of production systems by which investigation unit passed. The study staff up the analysis models of the trajectories of agricultural production units developed by Fritz Filho (2009), aggregate bound variables, above all, innovation. Research has incorporated elements derived from studies Oslo (2013); Saenz and García Capote (2002); Santos and Sanchez (2014); and Schumpeter (1988). As a result, technological innovation stands out in processes, products and forms of management, which increased the production and quality in the products and also increase the income and quality of life, through the management to be more professional. In addition, the study found the use of rural state credit as important to the trajectory of the investigation unit.
\end{abstract}

Keywords: Technological innovation; Production systems; Trajectories. 


\section{INTRODUÇÃO}

$\mathrm{Na}$ literatura tradicional, o setor da inovação na agricultura é descrito como dependente das inovações ocorridas no campo dos fornecedores de insumos agrícolas. Interpretações da Teoria Evolucionista defendem a possibilidade de analisar-se a agricultura pela lógica concorrencial e schumpeteriana, em que os agricultores buscam fazer a adoção de novas tecnologias com o propósito de aumentar sua participação no mercado, assim, como aumentar lucros de monopólio (SANTOS; SANCHEZ, 2014). Para Schumpeter (1988), a inovação tecnológica é fundamental para o desenvolvimento econômico e pode ser introduzida por uma forma diferente de produzir, pela incorporação de novas técnicas de produção e pela organização industrial e, ainda, por meio da utilização de novas combinações de recursos produtivos.

Por outro prisma, os subsídios destinados à agricultura cumprem um importante papel, tanto na modernização, quanto no que se refere ao próprio crescimento e ao aprimoramento alcançado com as novas tecnologias empregadas e os investimentos no setor. O progresso tecnológico é o "motor do crescimento", visto que atua diretamente sobre a produtividade, isto é, "o trabalho do homem ou de uma máquina se torna mais produtivo quando o nível de tecnologia aumenta" (SANTOS; SANCHEZ, 2014, p. 4). Para Fürstenau (1988), a disponibilidade de recursos com a finalidade de investimento é importante porque esse tipo de aplicação é responsável por introduzir ou ampliar o uso de técnicas mais produtivas, modificando os ganhos de produtividade da terra e do trabalho.

Em 1970, momento forte do processo de modernização agrícola no Brasil, o rápido crescimento da agricultura brasileira foi explicado, em grande parte, pela expansão da área cultivada, com a ajuda de programas de desenvolvimento regional e políticas de Estado ligadas à pesquisa e à extensão. Uma parte considerável dos incentivos favoráveis à modernização incluiu subsídios ao investimento agrícola e a linhas especiais de crédito rural. Mas o que possibilitou extraordinário crescimento da agricultura foi a produção em grandes áreas planas que favoreceram a mecanização do trabalho. A intensa modernização agrícola é comprovada pelo aumento significativo do número de tratores em uso, que passou de 3.380, em 1940, para 530.691, em 1980 (SOUZA, 2007).

Nessa concepção, a propriedade rural é considerada como pilar da produção de alimentos, com atividades de criação, produção de commodities, processamento, distribuição, beneficiamento, entre outras tantas, influenciando fortemente a economia e seus encadeamentos ${ }^{1}$.

Diante desse contexto, o objetivo principal deste artigo é analisar o impacto gerado pela inovação, pela tecnologia e pelas formas de gestão na trajetória de uma unidade de produção agrícola ${ }^{2}$ localizada no Estado do Rio Grande do Sul no município de Coxilha. Os elementos investigados referem-se às diferentes trajetórias da unidade de produção agrícola (UPA), sobretudo nos momentos de acesso e de incorporação de inovação tecnológica em processos, produtos e comercializações da produção. Como objetivos específicos, o estudo

\footnotetext{
$1 \quad$ Para ampliar a análise ver Souza (2007) e Albuquerque; Nicol (1987).

O texto trabalha com o conceito de UPA- Unidade de Produção Agrícola caracterizada pela propriedade rural seus meios de produção, capitais, mão-de-obra, investimentos entre outros elementos que constituem a UPA.
} 
visa: a) aplicar um modelo pautado em estudos de trajetórias de UPAs; b) caracterizar os tipos de inovações adotadas ao longo das trajetórias da UPA investigada; c) destacar a participação das políticas de Estado ligadas a inovações na trajetória da unidade de produção agrícola investigada; d) avaliar os avanços nas formas de gestão da UPA.

\section{INOVAÇÃO E AGRICULTURA}

O referencial teórico privilegia uma breve explanação de conceitos ligados sobretudo às relações entre inovação e agricultura no Brasil.

\subsection{Breve contexto}

A abordagem dos autores clássicos e neoclássicos destaca que a técnica e a tecnologia exercem um papel suplementar nos processos produtivos e a contribuição dessas é decisiva sob a ótica de marxistas, neosschumpeterianos e evolucionistas. Adam Smith, por usa vez, não se ateve à análise de aspectos sociais inerentes à introdução de novas tecnologias, como o desemprego tecnológico e as condições de trabalho (FRANTZ, 2012). David Ricardo abordou a questão da tecnologia como fator de poupança de mão de obra e foi o primeiro a destacar que a posse exclusiva de uma máquina pode conferir vantagens de monopólio temporário ao seu dono, no papel de detentor de nova e exclusiva tecnologia. Com as contribuições de Marx e Schumpeter, passou-se a perceber a busca por inovações radicais, com o intuito de assegurar ganhos excepcionais resultantes dessas. Karl Marx explica a origem da riqueza na produção de mais-valia, seja essa absoluta ou relativa. Quando os ganhos capitalistas são gerados em cenários tecnologicamente atrasados com exploração direta dos trabalhadores, tem-se a maisvalia absoluta, por meio de salários baixos, condições mínimas de trabalho e jornada de trabalho extensa. No momento em que se tem a introdução de novas tecnologias, consequentemente, há o aumento da produtividade, ao que Marx denomina de mais-valia relativa.

Entre os neoclássicos, o autor que ganha maior destaque é Joseph Alois Schumpeter, que mostra o papel preponderante da tecnologia no funcionamento da economia capitalista. Seguindo a lógica de Schumpeter (1988), o fator fundamental para o desenvolvimento econômico é a inovação tecnológica, que consiste em produzir de maneira diferente, incorporando novas técnicas de produção, utilizando novas combinações de recursos produtivos, promovendo a mudança. Assim, o desenvolvimento é definido pela realização de novas combinações.

\subsection{Inovações tecnológicas}

O conceito de inovação baseado na definição clássica do Schumpeter, conforme descrito em sua obra "A Teoria do Desenvolvimento Econômico", engloba cinco casos, a saber: 1) "Introdução de um novo bem". 2) "Introdução de um novo método de produção". 3) "Abertura de um novo mercado". 4) "Conquista de uma nova fonte de oferta de matériasprimas ou de bens semimanufaturados". 5) "Estabelecimento de uma nova organização de qualquer indústria" (SCHUMPETER, 1988, p. 48). 
Para Saenz e García Capote, as tecnologias, dependendo da fase ou do momento em que são aplicadas, podem ser classificadas da seguinte forma: "Tecnologia de produto, Tecnologia de processo, Tecnologia de distribuição, Tecnologia de consumo, Tecnologia de gerência ou gestão, e, Tecnologia social” (2002, p. 50 - 51).

Segundo o Manual de Oslo (2013), inovações tecnológicas em produtos e processos (TPP) "compreendem as implantações de produtos e processos tecnologicamente novos e substanciais melhorias tecnológicas em produtos e processos” (p. 54). A inovação tecnológica de produto pode assumir duas formas - produtos tecnologicamente novos e produtos tecnologicamente aprimorados. A inovação tecnológica de processo "é a adoção de métodos de produção novos ou significativamente melhorados, incluindo a entrega dos produtos" (p. 56). Esses métodos podem envolver mudanças nos equipamentos ou na organização da produção ou, ainda, abarcar uma combinação dessas mudanças que podem derivar do uso de novos conhecimentos.

Um exemplo seria um novo produto (tecnologia de produto) utilizado como matériaprima na tecnologia de processo de produção de determinados tipos de fertilizantes (tecnologia de produto). Tais fertilizantes são comercializados - entre outros usos - para o cultivo da soja (tecnologia de processo), destinada à produção do grão da soja (tecnologia de produto), que, ao ser utilizado para a indústria de rações, entra na tecnologia de processo de produção de diferentes produtos de consumo para a pecuária.

A inovação tecnológica pode ocorrer, tanto no processo de produção, quanto nos produtos de determinada empresa. A inovação organizacional inclui: introdução de estruturas organizacionais significativamente alteradas; implantação de técnicas de gerenciamento avançado; e implantação de orientações estratégicas novas ou substancialmente alteradas (OSLO, 2013, p. 62).

A inovação é um processo dinâmico, ou seja, todos os envolvidos aprendem continuamente com as experiências cotidianas, introduzindo modificações em produtos e processos para uma melhor adaptação da atividade desenvolvida com a introdução de inovações. Segundo Saenz e García Capote (2002), os processos inovadores se caracterizam por ser irregulares - realizam-se em diferentes etapas com múltiplas retroalimentações, interações e modificações, quais sejam: de alto risco - só uma pequena proporção de ideias tomadas, em consideração chega ao mercado como um novo produto, um novo processo ou um novo sistema; e, frequentemente lentos - é prolongado o lapso que transcorre entre a percepção de uma necessidade não satisfeita e a entrada de uma nova tecnologia para satisfazê-la.

Segundo Saenz e García Capote (2002), as inovações podem ser classificadas em dois tipos: inovações básicas ou radicais. Ambas constituem uma mudança histórica na maneira de fazer as coisas, abrem novos mercados, novas indústrias. A partir da ocorrência de tais inovações, surgem novos produtos, serviços e processos de produção; abrem-se novos campos para a aplicação de produtos ou serviços; brotam mudanças significativas nos parâmetros produtivos (eficiência, custos, produtividade e qualidade); despontam inovações incrementais ou de melhoria - aquelas que produzem melhorias nas tecnologias existentes, sem alterar suas características fundamentais e, também, inovações menores - as quais não representam uma mudança significativa sobre o nível tecnológico existente (design de um produto), ainda que apresentem um efeito econômico ou social. 
O impacto das inovações pode ser calculado por meio da análise precisa e detalhada do custo benefício, do prazo esperado de recuperação do custo ou do retorno decorrente de determinada inovação incorporada e, ainda, por meio da percepção de melhoria da qualidade do produto e/ou processo, do aumento da produção e da estabilidade de participação no mercado.

\subsection{A inovação na agricultura brasileira}

Vieira Filho (2014) faz um histórico da transformação da agricultura brasileira de 1960 a 2014, em que verifica a enorme transformação pela qual a agricultura passou. Para melhor compreensão do processo de transformação, o autor faz a divisão em três momentos, conforme Tabela 1. O primeiro compreende a década de 1960 até meados da década de 1970; o segundo inicia em meados da década de 1970 e vai até por volta do início da década de 1990; e o terceiro, último momento, segue do início da década de 1990 até 2014.

Tabela 1: Descrição dos fatos relevantes de análise histórica da agricultura brasileira Momento Descrição dos fatos relevante

Em 1960, a produção da soja alcança a importância já conquistada pela produção de trigo na região Sul do país; em 1965, a produção de suínos e aves cria demanda por farelo de soja,

Primeiro importante fonte de proteína vegetal na alimentação animal; criação do Sistema Nacional de

$(1960-1970)$ Crédito Rural (SNCR), instituído pelo governo federal, em 1965; Criação da Embrapa Brasileira de Pesquisa Agropecuária (Embrapa), em 1973, empresa fundamental para a organização de uma estratégia nacional de pesquisa agropecuária.

Criação da Embrapa Soja, em 1975, no Estado do Paraná, região pioneira no cultivo de grãos; criação do Programa Nacional do Álcool (Pró-Álcool), em 1975. O programa consistia na substituição de combustível fóssil, derivado do petróleo, por álcool; realização de pesquisas para adaptar mudas e sementes resistentes ao clima mais seco e quente dos

Segundo

(1970 - 1990) cerrados. Tais pesquisas foram fundamentais para expansão da fronteira agrícola no Brasil em direção ao Centro-Oeste; a promoção do manejo integrado de pragas. Na década de 1980, em pesquisa desenvolvida pela Embrapa, a inoculação de bactérias (que captam o nitrogênio do solo) na semente de soja permitiu o crescimento da produção com menor uso de fertilizantes, contribuindo para o aumento da escala produtiva, com maior produtividade por área plantada. Com o aumento da escala produtiva no Centro-Oeste, promoveu-se a mecanização, facilitada pela característica do terreno (planaltos) e pelo baixo custo da terra.

Massificação do plantio direto, com aumento da qualidade das sementes; forte transformação institucional da economia brasileira, abertura de mercado e estabilização monetária (Plano Real); criação de programas de financiamento e de investimento na segunda metade da década de 1990. Em 1996, instituiu-se o Programa de Modernização da Frota de Tratores Agrícolas e Implementos Associados e Colheitadeiras (Moderfrota). Com o aumento do volume de crédito ao logo dos últimos 15 anos, tal programa foi importante na renovação da frota de tratores e colheitadeiras na agricultura brasileira. Em 1995, foi criada a Medida Provisória de Biossegurança, que foi promulgada e atualizada em 2005; o marco regulatório brasileiro referente à propriedade intelectual passou por transformações em 1995, com a assinatura do acordo internacional (Trips). Em 1997, criou-se a Lei de Proteção

Terceiro
$(1990-2014)$ de Cultivares (LPC). A partir de 2002, houve forte crescimento da economia internacional, puxada pelo crescimento das economias emergentes, o que demandou maior consumo de alimentos. Em 1997, verificou-se o primeiro plantio de soja geneticamente modificada. A legalização do plantio de cultivares geneticamente modificadas se dará posteriormente, sendo a soja em 2003, o algodão em 2005 e o milho em 2008. O plantio de organismos geneticamente modificados simplifica o manejo e as práticas agrícolas, reduzindo o uso de herbicidas e pragas, e aumentando a renda disponível dos produtores. Há, ainda, a segunda expansão da fronteira agrícola em direção à região do Matopiba (Maranhão, Tocantins, Piauí e Bahia) e a adoção de práticas agrícolas de precisão, no intuito de aumentar a eficiência no uso de recursos produtivos.

Fonte: Vieira Filho (2014, p. 400 - 401). 
Mais importante que a tecnologia é a sua difusão. Para Saenz e García Capote (2002), a difusão tecnológica é determinante, caracterizando-se o processo pelo qual uma inovação, a partir da sua introdução, estende-se ou generaliza-se em canais comerciais ou não comerciais, para diferentes países e regiões, assim como para diferentes indústrias, mercados e empresas.

Figura 1: Inovação, ciência e tecnologia na organização da atividade agrícola

\section{Organização da atividade agrícola}

\section{Setor fornecedor}

\begin{tabular}{l} 
Mecânica \\
Máquinas \\
Implementos \\
Equipamentos de irrigação \\
Aviação agrícola \\
\multicolumn{1}{|c|}{ Química } \\
Fertilizantes \\
Defensivos \\
\multicolumn{1}{|c|}{ Biológica } \\
Sementes \\
Micro-organismos \\
Controlł biológico \\
Melhoramento genético \\
Transgênicos \\
\hline \multicolumn{1}{|c}{$\uparrow$} \\
Pesquisa e desenvolvimento \\
público e privado
\end{tabular}

Distribuição

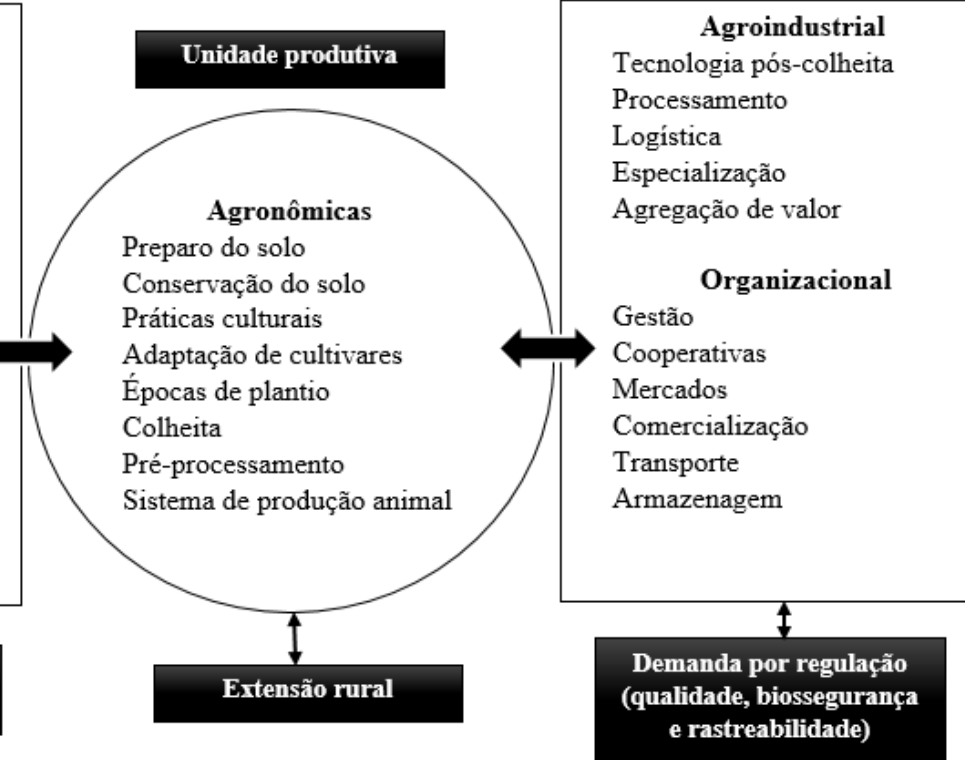

Fonte: Vieira Filho (2009) apud Vieira Filho (2012).

A inovação é introduzida por uma empresa e/ou entidade, passando a ser utilizada por outras instituições pares. A difusão transcende a transferência ou a aquisição de tecnologia, tais como licenças, maquinarias, equipamentos, etc. e a assimilação dessas. Trata-se de um processo lento que acompanha uma série de inovações incrementais ou menores a fim de: ajustar a tecnologia às condições particulares de uso; ampliar a gama de aplicações; melhorar a qualidade do produto ou torná-lo mais atrativo a seus usuários; incrementar a eficiência e reduzir os custos dos processos de produção e distribuição.

Para Vieira Filho (2012), a organização da atividade agrícola é definida em sentido amplo, uma vez que não envolve apenas as atividades desenvolvidas na unidade agrícola, mas envolve também um amplo sistema de pesquisa, ciência, inovação e tecnologia, conforme mostra a Figura 1.

Entre o apoio institucional e a inovação na agricultura, atualmente, há que se destacar a Política Nacional de Assistência Técnica e Extensão Rural (Pnater), construída em parceria com as organizações governamentais e não governamentais de Assistência Técnica e Extensão Rural (Ater), em conjunto com a sociedade civil organizada. Tal política foi instituída pelo Governo Federal em 2003 e fomenta a produção de tecnologias e de conhecimento apropriados para a agricultura familiar, ou seja, apoia projetos de validação, teste e disponibilização de tecnologias que respondam a demandas da agricultura familiar das diferentes regiões do País (MINISTÉRIO DO DESENVOLVIMENTO AGRÁRIO, 2015). 
Em outro eixo, foram criados Fundos Setoriais, a partir de 1999, com o objetivo de incentivar o desenvolvimento científico e tecnológico em áreas estratégicas, além de construir um novo mecanismo de financiamento de investimentos. Esses, prioritariamente, visam a financiar o fomento tecnológico, os projetos cooperativos, as redes de pesquisas e os projetos estruturantes (VIEIRA FILHO, 2012).

Já o Plano de Ação Conjunta (Paiss Agrícola) objetiva coordenar ações de fomento à inovação e ao aprimoramento da integração dos instrumentos de apoio disponibilizados pelo BNDES e pela Financiadora de Estudos e Projetos (Finep), com o propósito de fomentar tanto o desenvolvimento e a produção pioneira de tecnologias agrícolas como a adaptação de sistemas industriais (BNDES, 2015).

Adicionalmente, o BNDES Finame Agrícola é um financiamento cujas operações são realizadas por intermédio de uma instituição financeira credenciada, seguindo a modalidade indireta e automática de apoio. Os itens financiáveis são: máquinas, implementos agrícolas e bens de informática e de automação novos, incluídos conjuntos e sistemas industriais, destinados à produção agropecuária e produzidos no Brasil (BNDES, 2015).

\section{METODOLOGIA}

\subsection{Unidade de análise}

A unidade de análise compreende uma propriedade rural localizada no município de Coxilha-RS que apresenta um sistema de produção comum a outros sistemas desenvolvidos na região Noroeste do Estado do Rio Grande do Sul ${ }^{3}$.

A propriedade é classificada como pequena propriedade rural familiar, com uma área de 51 hectares (ha) que equivalem a 3,1 módulos fiscais.

\subsection{Modelo proposto}

A análise da trajetória foi pautada nos modelos de análise das trajetórias de Unidades de Produção agrícola desenvolvidos por Fritz Filho (2009), com a agregação de variáveis ligadas, sobretudo, à inovação. O Modelo incorporou elementos derivados de estudos de Oslo (2013); Saenz e García Capote (2002); Santos e Sanchez (2014); e, Schumpeter (1988), que contribuíram para a escolha das variáveis de análise e para a proposição de um modelo que desse conta da problemática abordada pelo estudo. As variáveis propostas buscam caracterizar a unidade produtiva estudada, descrever sua trajetória desde o início das atividades e, por fim, dimensionar o impacto gerado pelas inovações tecnológicas.

O histórico da unidade de produção agrícola permite compreender como foram adquiridos os principais meios de produção disponíveis, e como funciona o sistema de produção atual. A análise da trajetória de evolução oportuniza verificar qual a situação da unidade, ou em outras palavras: avaliar se encontra-se em uma situação "boa (de bem-estar)", quais foram suas principais evoluções e como a inovação e a tecnologia contribuíram para isso. A análise da história investiga se a família tem renda de outras atividades, as razões porque o sistema de produção evoluiu progressivamente. Por meio da análise tecnológica, é

Ver Rückert (2003), Silva Neto (2005), Miguel (2009). 
possível caracterizar a manutenção e o nível de substituição dos equipamentos (ampliação tecnológica) e os seus impactos diretos e indiretos e, ainda, analisar a evolução das técnicas agrícolas e o seu impacto sobre o futuro da unidade de produção. ${ }^{4}$

\subsection{Estratégias de pesquisa e evidências ou fontes de dados ${ }^{5}$}

A estratégia de estudo utilizada é do tipo estudo de caso único, que, segundo Yin (2010), além de permitir entender os fenômenos sociais complexos, também permite que os investigadores retenham as características holísticas e significativas dos eventos da vida real. Nesse propósito, foram utilizadas as fontes (ou evidências) que seguem.

a) Entrevista em profundidade - realizada com os proprietários foi pautada em dois pontos principais, identificação de elementos e eventos que contribuíram para as mudanças na estrutura produtiva e técnica ao longo da trajetória de evolução da UPA. Em segundo momento, iniciou-se uma identificação das incorporações tecnológicas inseridas nos processos produtivos atuais, buscando evidenciar de que forma as tecnologias impactaram no processo produtivo da unidade e propiciaram o seu desenvolvimento, a partir de variáveis como os fatores que colaboraram para a modificação das atividades na unidade produtiva, inovação de produto, inovação de processo.

b) Observações diretas - as observações diretas foram realizadas durante a visita de campo, o que possibilitou observações das condições de infraestrutura, dos locais de trabalho e demais observações que se fizeram pertinentes no momento.

c) Documentação - foram arrolados contratos e notas fiscais de compra de máquinas e implementos, entre outros documentos.

d) Registros em arquivo - os registros constituíram-se em fotos adquiridas e liberadas pelos proprietários, além de agendas com anotações e informações da realização das atividades na unidade.

\subsection{Eixos condutores do estudo}

Delimitadas as fontes de evidência, foi possível levantar as variáveis por meio de três eixos condutores: i) caracterização produtiva da unidade de produção agrícola; ii) estudo da trajetória da unidade agrícola sob a óptica dos processos tecnológicos, da inovação e da política para agricultura; e, iii) análise de impacto das inovações tecnológicas nos processos produtivos da unidade agrícola ao longo do tempo.

\subsubsection{Variáveis do estudo}

O primeiro quadro contempla variáveis e indicadores ligados aos aspectos da estrutura produtiva da unidade de produção agrícola investigada. O segundo quadro de variáveis permitiu identificar a trajetória da unidade produtiva analisada, a partir da história da propriedade e da lógica de evolução de cada sistema produtivo pautada na evolução tecnológica e produtiva. E o terceiro quadro de variáveis buscou identificar os impactos das

Adaptado do estudo de Fritz Filho (2009).

Baseado em Yin (2010). 
inovações tecnológicas nos processos da unidade produtiva, a partir da identificação das inovações de produto, de processo e de investimentos em maquinário e implementos.

Quadro 1: Variáveis e indicadores da caracterização produtiva da UPA do município de Coxilha/RS

\begin{tabular}{|l|l|}
\hline \multicolumn{2}{|c|}{ VARIÁVEIS } \\
\hline Área & Posse da terra (em ha*). \\
\hline Atividades realizadas na unidade de produção & $\begin{array}{l}\text { Área (ha), faturamento, comercialização (externa, } \\
\text { consumo na unidade) por tipo de culturas, tipo de } \\
\text { criação e outras atividades. }\end{array}$ \\
\hline Receitas de outras atividades & Valor e tipo de receitas. \\
\hline Financiamento & Valor e tipo de financiamento. \\
\hline Mão de obra & $\begin{array}{l}\text { Modalidade, idade, número de pessoas, escolaridade e } \\
\text { funções por tipo de mão de obra. }\end{array}$ \\
\hline Máquinas, equipamentos e benfeitorias & $\begin{array}{l}\text { Tipo, quantidade e estado das máquinas, equipamentos } \\
\text { e benfeitorias. }\end{array}$ \\
\hline Permanência dos filhos na unidade & $\begin{array}{l}\text { Número de filhos que residem na unidade de produção, } \\
\text { escolaridade dos filhos e intenção de permanência nas } \\
\text { atividades vinculadas à unidade de produção. }\end{array}$ \\
\hline Objetivos do produtor quanto à unidade de produção & $\begin{array}{l}\text { Permanência do produtor e suas intenções em relação à } \\
\text { unidade de produção. }\end{array}$ \\
\hline Formas de gestão ${ }^{6}$ & $\begin{array}{l}\text { Formas de gestão, em específico, forma como era } \\
\text { realizado o planejamento, a organização, a direção, o } \\
\text { controle, na área financeira, na comercialização e na } \\
\text { área de produção. }\end{array}$ \\
\hline
\end{tabular}

Fonte: Adaptado do modelo de Fritz Filho (2009).

Quadro 2: Variáveis e indicadores - histórico - da trajetória da UPA do município de Coxilha/RS

\begin{tabular}{|c|c|}
\hline VARIÁVEIS & INDICADORES \\
\hline História da propriedade & Relato do período e razões para o início das atividades na unidade de produção. \\
\hline \multirow{10}{*}{$\begin{array}{l}\text { Reconstituição dos } \\
\text { principais momentos da } \\
\text { evolução da unidade }\end{array}$} & $\begin{array}{l}\text { Modificações sofridas pela unidade (área, sistema produtivo, mão de obra, } \\
\text { atividades...). }\end{array}$ \\
\hline & Área. \\
\hline & Atividades produtivas (em relação a culturas, criação e outras atividades). \\
\hline & Ampliação de tecnologia (se amplia, de que forma amplia os recursos). \\
\hline & Formas de ampliação tecnológica. \\
\hline & $\begin{array}{l}\text { Fatores que colaboraram para a mudança das atividades da unidade (mudanças } \\
\text { técnicas, intervenção do Estado, mão de obra, falta de mercado, outra). }\end{array}$ \\
\hline & Uso de políticas públicas (empréstimos financiamentos). \\
\hline & $\begin{array}{l}\text { Obtenção de crédito agrícola (que importância teve o crédito para a implantação e } \\
\text { manutenção do sistema de produção). }\end{array}$ \\
\hline & $\begin{array}{l}\text { Os investimentos que impactaram significativamente para o desenvolvimento da } \\
\text { unidade. }\end{array}$ \\
\hline & $\begin{array}{l}\text { Formas de gestão, em específico, forma como era realizado o planejamento, a } \\
\text { organização, a direção, o controle, na área financeira, na comercialização e na área } \\
\text { de produção. }\end{array}$ \\
\hline
\end{tabular}

Fonte: Adaptado do modelo de Fritz Filho (2009).

6 Variáveis adaptadas a partir do estudo de Salume, Silva \& Christo (2015). 
Quadro 3: Variáveis e indicadores do impacto das inovações tecnológicas nos processos produtivos da UPA do município de Coxilha/RS

\begin{tabular}{|c|c|}
\hline VARIÁVEIS & $\begin{array}{l}\text { INDICADORES } \\
\end{array}$ \\
\hline $\begin{array}{l}\text { Fatores que colaboraram para a } \\
\text { modificação das atividades na unidade } \\
\text { produtiva com novas tecnologias no } \\
\text { processo produtivo }\end{array}$ & $\begin{array}{l}\text { Incentivos do governo: Proagro, Pronaf entre outros (utilização, se } \\
\text { utilizou porque foi importante). } \\
\text { Crédito Rural (utilização, tipo de fonte - privada ou pública - porque } \\
\text { foi importante). }\end{array}$ \\
\hline Associações e Cooperativas & $\begin{array}{l}\text { Associação a alguma Associação ou Cooperativa (há quanto tempo, } \\
\text { quais os benefícios). }\end{array}$ \\
\hline Inovação de produto & $\begin{array}{l}\text { Produção e venda de algum produto diferente do que fazia } \\
\text { anteriormente. }\end{array}$ \\
\hline Inovação de processo & $\begin{array}{l}\text { Utilização de alguma técnica de produção nova que não utilizava } \\
\text { anteriormente. } \\
\text { Utilização de novas características organizacionais e de gestão. }\end{array}$ \\
\hline \multirow{2}{*}{$\begin{array}{l}\text { Ampliação tecnológica - inovação } \\
\text { mecânica }\end{array}$} & $\begin{array}{l}\text { Investimento em máquinas, equipamentos e implementos agrícolas } \\
\text { mais modernos e tecnológicos. } \\
\text { Impactou nos processos produtivos decorrente das aquisições. }\end{array}$ \\
\hline & $\begin{array}{l}\text { Forma pela qual adquiriu os recursos tecnológicos (política de } \\
\text { crédito, empréstimos, venda de ativos - terra, máquina - faturamentos } \\
\text { da unidade...). }\end{array}$ \\
\hline $\begin{array}{l}\text { Fonte de tecnologia dos fornecedores de } \\
\text { insumos (rações, defensivos agrícolas, } \\
\text { fertilizantes - sementes...) - Inovação } \\
\text { química }\end{array}$ & $\begin{array}{l}\text { Importância dada à inovação e tecnologia por parte dos fornecedores } \\
\text { (em que auxilia na unidade produtiva). }\end{array}$ \\
\hline \multirow{2}{*}{ Extensão rural } & $\begin{array}{l}\text { Participa de extensões rurais, a fim de, aprimorar os conhecimentos } \\
\text { (feiras agrícolas, dia de campo, palestras, cursos...). }\end{array}$ \\
\hline & $\begin{array}{l}\text { Importância dada ao desenvolvimento de conhecimento para executar } \\
\text { as atividades na unidade. }\end{array}$ \\
\hline
\end{tabular}

Fonte: Adaptado do modelo de Fritz Filho (2009).

\subsection{Síntese do modelo de análise aplicado}

A análise da trajetória da unidade de produção agrícola estudada foi efetuada por meio da estrutura de análise ilustrada a seguir, que contempla o sistema produtivo e a passagem para um novo sistema, considerando os fatores internos e externos à unidade produtiva.

Figura 2: Estrutura da síntese da trajetória do sistema produtivo da UPA do município de Coxilha sob a óptica do processo de evolução tecnológica

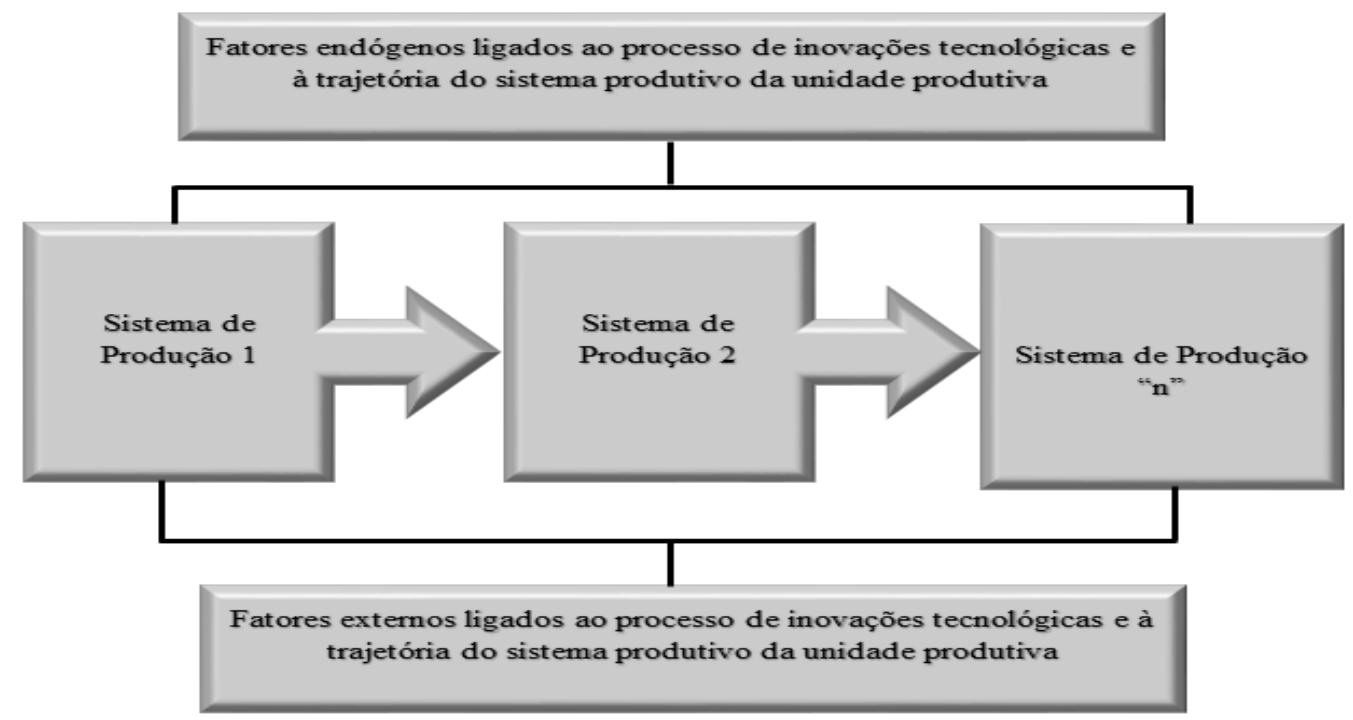

Fonte: Adaptado do modelo de Fritz Filho (2009). 


\section{RESULTADOS}

A seguir são apresentados os resultados da pesquisa. Inicialmente, é apresentado o sistema de produção vigente. Em seguida, há a reconstrução das distintas trajetórias percorridas na UPA desde sua implantação, com atenção especial para os impactos advindos da incorporação das inovações tecnológicas e formas de gestão, objetos desse estudo.

\subsection{Descrição das atividades vigentes na UPA}

A unidade de produção em estudo localiza-se a $10 \mathrm{~km}$ da área central do município de Coxilha, região da Produção, norte do RS. Conta com uma área total de 51 ha, dos quais, em cerca de 1 ha, estão localizadas as moradias dos produtores e há mata nativa. Nos 50 ha restantes concentram-se as atividades produtivas. A seguir, na Tabela 2, estão distribuídas as atividades de produção vegetal, pecuária e demais atividades da UPA.

É feita a comercialização de soja, milho e trigo por meio de venda externa a uma cooperativa, já a aveia e as pastagens são para o consumo do gado de corte e leiteiro da unidade. A unidade conta com a criação de bovinos (ciclo completo), e produção de leite para indústria (3.500 litros/mês) e para consumo próprio na unidade (2 litros/dia). Além disso, também se criam frangos e poedeiras para consumo de carne de frango e ovos na unidade. É realizada a comercialização, em pequena quantidade, de bovinos prontos para abate (frigoríficos). Além das atividades já mencionadas, há as atividades de horta e pomar, a plantação de feijão e mandioca para consumo próprio na unidade. Não há receitas de rendas adicionais, somente a aposentadoria do casal fundador da unidade agrícola.

Tabela 2: Principais atividades da produção agrícola, pecuária e demais atividades da UPA

\begin{tabular}{c|c|c|c}
\hline Descrição da atividade & Tipo & Quantidade & Comercialização \\
\hline \multirow{3}{*}{ Produção Vegetal } & Soja & 28 ha & Cooperativa \\
& Milho & 10 ha & Cooperativa \\
& Trigo & 5 ha & Cooperativa \\
& Aveia & $3 \mathrm{ha}$ & Consumo dos bovinos \\
& Pastagens & $2 \mathrm{ha}$ & Consumo dos bovinos \\
\hline \multirow{3}{*}{ Produção Pecuária } & Gado de corte & varia de 5 a 10 & Frigoríficos \\
& Gado de leite & varia de 10 a 12 & Indústria \\
& Frangos, poedeiras & variam de 5 a 10 cada & Consumo próprio \\
\hline \multirow{2}{*}{ Outras Atividades } & Horta, pomar, plantação de & 1 & Consumo próprio \\
\hline
\end{tabular}

Fonte: Dados de Pesquisa, 2015.

Mão de obra - A unidade conta com mão de obra unicamente familiar, três pessoas ligadas intensamente às atividades desenvolvidas, com idade acima de quarenta anos, com escolaridade fundamental, desempenham as atividades das lavouras (produção vegetal), a plantação, o manejo e a colheita e, também, a criação de gado e o manejo da produção leiteira.

Máquinas, equipamentos e benfeitorias - A UPA conta com três galpões, um caminhão, um carroção basculante, uma camionete, quatro tratores, uma grade, duas semeadeiras, dois pulverizadores, uma ordenhadeira, um tanque de expansão, uma colheitadeira e uma adubadora. Os equipamentos e benfeitorias foram adquiridos de renda 
própria proveniente das atividades desenvolvidas na unidade (venda de grãos, madeira, porcos e leite).

Sucessão na unidade - $O$ casal fundador que iniciou as atividades na unidade, em 1951, teve seis filhos, dos quais, dois permaneceram na unidade e seguem até hoje. Um desses teve três filhos que residem na unidade, os quais participam apenas eventualmente das atividades (finais de semana, férias), pois um estuda e trabalha fora e outro ainda é criança. Eles objetivam continuar na unidade, pois pretendem manter a produção das lavouras, mesmo estando trabalhando na cidade.

Objetivos do produtor em relação à unidade de produção agrícola - Os produtores pretendem permanecer na unidade com objetivo de ampliação de área de cultivo. Almejam investir em novas tecnologias como a aquisição de uma nova colheitadeira.

Quanto aos mecanismos de gestão, os proprietários aplicam o planejamento, a organização e o controle sobre a UPA e também sobre as atividades nela desenvolvidas. A seguir, no Quadro 4, uma síntese.

Quadro 4: Mecanismos de gestão da unidade de produção agrícola

\begin{tabular}{|c|c|}
\hline Planejamento & $\begin{array}{l}\text { Para fazer o levantamento de custos de produção, para a compra de sementes, } \\
\text { fertilizantes e defensivos para a plantação de grãos e para a produção leiteira, fazem } \\
\text { o levantamento de custo de rações, medicamentos etc.? }\end{array}$ \\
\hline Organização & $\begin{array}{l}\text { Possuem máquinas e instalações adequadas, têm acesso a máquinas que auxiliam na } \\
\text { produção, tudo por meio de recursos próprios? }\end{array}$ \\
\hline Direção & $\begin{array}{l}\text { Buscam informações para melhoria da condução da propriedade, para acompanhar as } \\
\text { mudanças e poder melhorar as atividades desenvolvidas por meio do Sindicato, da } \\
\text { Cooperativa e da Emater? Participam de palestras e dias de campo? }\end{array}$ \\
\hline Controle & $\begin{array}{l}\text { Realizam o controle das perdas, calculando-se as perdas para verificar o impacto } \\
\text { dessas sobre o lucro, avaliando se foi possível cobrir os custos despendidos para a } \\
\text { produção? Eventualmente, é realizado o controle de estoque, pois, eles admitem } \\
\text { saber exatamente o que possuem em estoque? }\end{array}$ \\
\hline Área Financeira & $\begin{array}{l}\text { Reinvestem o lucro na propriedade, em melhorias necessárias como aquisição de } \\
\text { novas máquinas, implementos, na estrutura, custear gastos imprevistos e para o novo } \\
\text { ciclo de produção. Consideram que a unidade possui bom controle financeiro, pois, } \\
\text { procuram manter a estabilidade, sem gerar dívidas extensas e que não possam pagar. }\end{array}$ \\
\hline Comercialização & $\begin{array}{l}\text { Comercializam os produtos por meio de uma Cooperativa? Consideram o preço pago } \\
\text { pelos produtos regular, porque os preços de alguns produtos (milho, trigo, leite) são } \\
\text { baixos e, às vezes, não compensam os custos e a mão de obra? }\end{array}$ \\
\hline Área de Produção & $\begin{array}{l}\text { Na produção leiteira, possuem o tanque de expansão, visando manter a qualidade do } \\
\text { leite no tempo em que permanece na propriedade e, utilizam genética melhorada? Na } \\
\text { produção de grãos, investem em sementes que permitem melhor qualidade do grão e } \\
\text { maior produtividade e, em máquinas e implementos que auxiliam intensamente no } \\
\text { processo produtivo? }\end{array}$ \\
\hline
\end{tabular}

Fonte: Dados de Pesquisa, 2015.

\subsection{Análise da trajetória de evolução da UPA sob a óptica da inovação, tecnologia e formas de gestão: elementos de transição entre os sistemas de produção}

A evolução e a modernização da agricultura ao longo dos anos, em conjunto com as transformações da região do município conduziu a mudanças nos processos produtivos da unidade analisada, sob a óptica do impacto sofrido pela incorporação de inovações ao longo de sua história. Para a identificação da evolução da unidade foram analisados os fatores que 
contribuíram para essas metamorfoses, colocando em tela as diferentes trajetórias realizadas pelos produtores em sua unidade de produção.

\subsubsection{Sistema de produção 1 (1951 - 1975) - lavoura, leite, criação e subsistência}

O produtor iniciou suas atividades na unidade em 1951, quando ali residia com sua esposa, mais tarde, com os filhos. Em uma área de 18 ha com produção agrícola voltada para culturas de subsistência e produção de grãos com finalidade comercial. A madeira foi uma significativa fonte de renda nesse período. No processo produtivo contava com equipamentos rudimentares como junta de bois, arado, grade e apenas um trator. Mais tarde adquiriu uma semeadeira (1970) e uma colheitadeira usada (1975), que geraram uma mudança histórica na maneira de fazer as coisas, ou seja, na maneira de executar o processo de produção, implicando em uma inovação radical como descrita por Saenz e García Capote (2002), nos processos.

4.2.2 Elementos de transição entre o Sistema de Produção 1 (lavoura, leite, criação e subsistência) e o Sistema de Produção 2 (lavoura, suinocultura, avanço tecnológico em inovações radicais)

Na transição para o Sistema de Produção 2, o produtor manteve-se com as mesmas atividades, apenas ampliando a área plantada e o esgotamento da madeira para comercialização. Na fase de transição (Figura 3), são incorporados máquinas e implementos agrícolas às atividades, as quais deixam de ser realizadas de forma rudimentar. Além disso, passa-se a executar a atividade de suinocultura, sob o estímulo do preço alto na comercialização do suíno e, também, pela disponibilidade de mão de obra, pois o produtor contava com a ajuda dos filhos nessa fase. Outro fator importante foi a utilização de linhas de crédito como o Pronaf e Proagro para custeio da produção de soja e milho, a partir da década de 1990.

Figura 3: Elementos, internos e externos, determinantes para a Passagem do Sistema 1 para o Sistema 2 na unidade produtiva

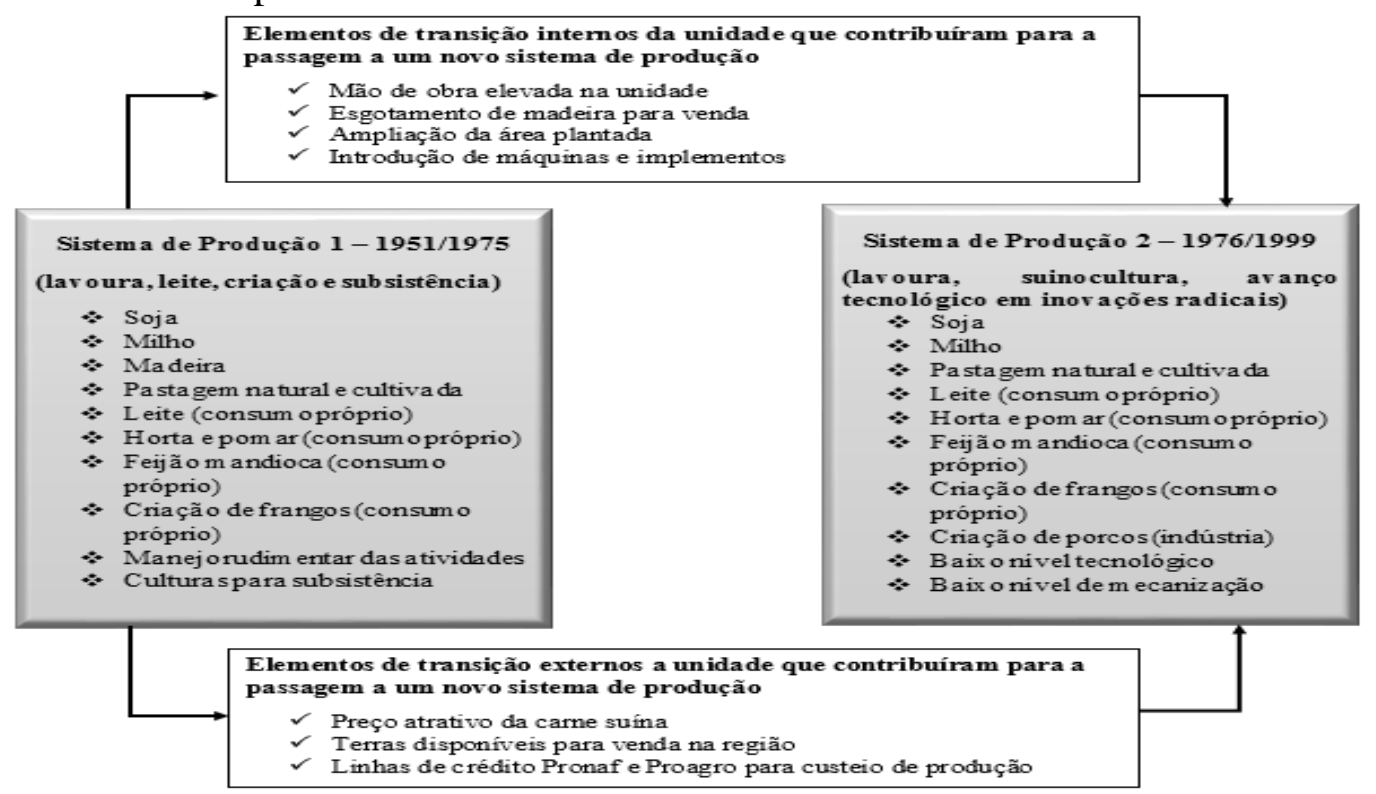

Fonte: Dados de Pesquisa, 2015. 


\subsubsection{Sistema de produção 2 (1976 - 1999) - lavoura, suinocultura, avanço tecnológico em inovações radicais}

Esse Sistema de Produção foi composto pela atividade de suinocultura - inovação de produto - executada na unidade com a ajuda dos filhos, do casal fundador da unidade. Além das culturas de subsistência e das já desenvolvidas no Sistema de Produção 1, houve ampliação das lavouras, ou seja, ampliou a área de plantações de soja e milho. Assim, apresenta um avanço tecnológico em inovações radicais, pois, as atividades deixaram de ser executadas de forma rudimentar, passando a serem mecanizadas, a partir do ano de 1970, com a introdução de colheitadeira, trator, semeadeira e caminhão, constituiu uma mudança no processo de produção.

Houve a ampliação de benfeitorias, foi construído um novo galpão para armazenagem adequada das máquinas e dos equipamentos, como também para os insumos utilizados na produção, como sementes, fertilizantes, defensivos entre outros. Pode-se dizer que é uma tecnologia de distribuição, visto que é um armazenamento adequado (temperatura, umidade, forma de armazenagem...), conforme Saenz e García Capote (2002, p. 50 - 51). Considerando, ainda, que a falta de infraestrutura prejudica as atividades de inovação (OSLO, 2013, p. 81). No final desse período, alguns dos filhos acabaram saindo da unidade, herdando alguns hectares de terras para construírem sua própria vida. Então, ficam na unidade, o fundador e mais dois filhos que continuaram a condução das atividades.

\subsubsection{Elementos de transição entre o Sistema de Produção 2 (lavoura, suinocultura, avanço tecnológico em inovações radicais) e o Sistema de Produção 3 (lavoura, leite, máquinas e implementos mais modernos)}

Na transição para o Sistema de Produção 3, os produtores ampliaram a área plantada e inseriram, além da cultura da soja e do milho, as culturas de trigo e aveia. Um dos produtores passou a comercializar leite para a indústria, que na época era a Parmalat. No ano de 2000, adquiriu uma ordenhadeira para facilitar o processo, o que se considera uma inovação tecnológica, pois, gerou melhorias no processo, antes executado manualmente, e no produto leite. Também, considerada uma inovação radical.

No início, o leite era armazenado em tarros dentro de um resfriador, posteriormente, em 2007, foi adquirido um tanque de expansão, outra inovação radical por processo, e também, tecnologia de distribuição. Outro produtor passou a se dedicar a um pequeno rebanho de corte. O cultivo das pastagens e da aveia era importante para a alimentação do gado de corte e leiteiro. A atividade de suinocultura foi esgotada, por volta de 2004/2005, pois, a mão de obra da unidade ficou reduzida com a saída de alguns filhos dos fundadores e também por falta de mercado e o baixo preço que passou a não compensar os custos e a execução da atividade. Percebe-se, nesse período, então, que aumentou significativamente a inovação e a tecnologia na unidade, inovações radicais, pois, todas as atividades passaram a ser mecanizadas, portanto, houve mudanças nos processos, também com a nova técnica de plantio direto, derivando em inovações tecnológicas nos processos.

Em 2000, os produtores trocaram de colheitadeira, adquirindo, semeadeira e pulverizador novos, e nesse período, compraram ainda três tratores. E mais adiante um dos produtores ainda adquiriu mais uma semeadeira e um pulverizador, para atender a uma área 
de terra herdada pela esposa. Essa renovação de maquinaria e implementos configura-se como inovações incrementais, ou seja, que preenchem o processo de mudanças (modernização) sem alterar as características fundamentais da tecnologia já existente, deriva do aprimoramento incremental da tecnologia existente (OSLO, 2013). A síntese dos fatores que contribuíram para a transição da unidade do Sistema de Produção 2 para o Sistema de Produção 3 é apresentado na Figura 4.

Figura 4: Elementos, internos e externos, determinantes para a passagem do Sistema 2 para o Sistema 3 na unidade produtiva

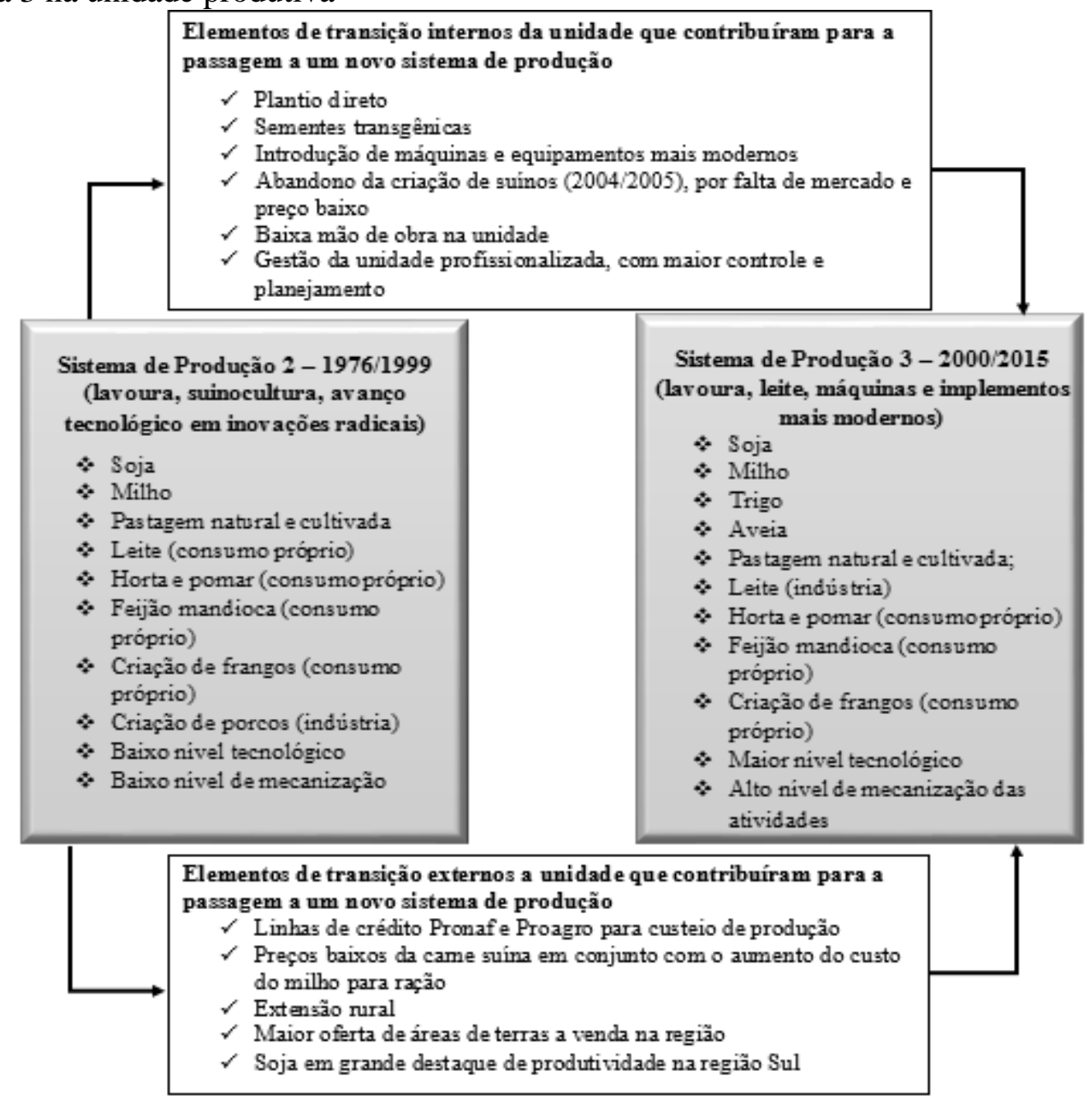

Fonte: Dados de Pesquisa, 2015.

\subsubsection{Sistema de produção $3(2000$ - 2015) - Atual - (lavoura, leite, máquinas e implementos modernos)}

Esse sistema conta com o fundador da unidade e mais dois filhos que se mantiveram na unidade. A característica principal do sistema de produção atual é a lavoura com as culturas de soja, milho, trigo e aveia (o que é considerado inovação de produto), em que há a introdução das culturas de trigo e aveia; a comercialização do leite para a indústria por parte de um dos produtores, o que se classifica como inovação de processo tecnológico, ou seja: “é a implantação/adoção de métodos de produção ou comercialização novos ou significativamente aprimorados" (OSLO, 2013, p. 21). A estratégia de investimentos em 
inovação e tecnologia, a partir do Sistema de Produção 2, foi fundamental para melhor executar as atividades e aumentar a produtividade e o faturamento na unidade, inovações radicais, tornando possível concretizar mudanças significativas nos parâmetros produtivos como eficiência, custos, produtividade e qualidade. Com esses investimentos, os produtores puderam fazer novas benfeitorias como as que passamos a elencar a seguir. Em 2005, foi construído um galpão pré-moldado, todo de material. Também foram adquiridas máquinas e implementos modernos, inovações incrementais ou menores, e, ainda, implementadas novas técnicas de produção, inovação tecnológica de processo. Destaque-se que a utilização de sementes transgênicas e fertilizantes e defensivos agrícolas possibilita usufruir de novas combinações dos recursos produtivos, considera-se também tecnologia de processo (OSLO, 2013).

Nesse sistema de gestão, por mais informal que seja, há mais controle e planejamento do que nos sistemas anteriores - inovação organizacional - demonstrando uma gestão profissionalizada.

\subsubsection{Síntese da dinâmica dos sistemas de produção - principais trajetórias}

A trajetória da unidade de produção caracteriza-se pela passagem por três sistemas de produção ao longo do tempo.

Figura 5: A dinâmica dos sistemas de produção: principais trajetórias

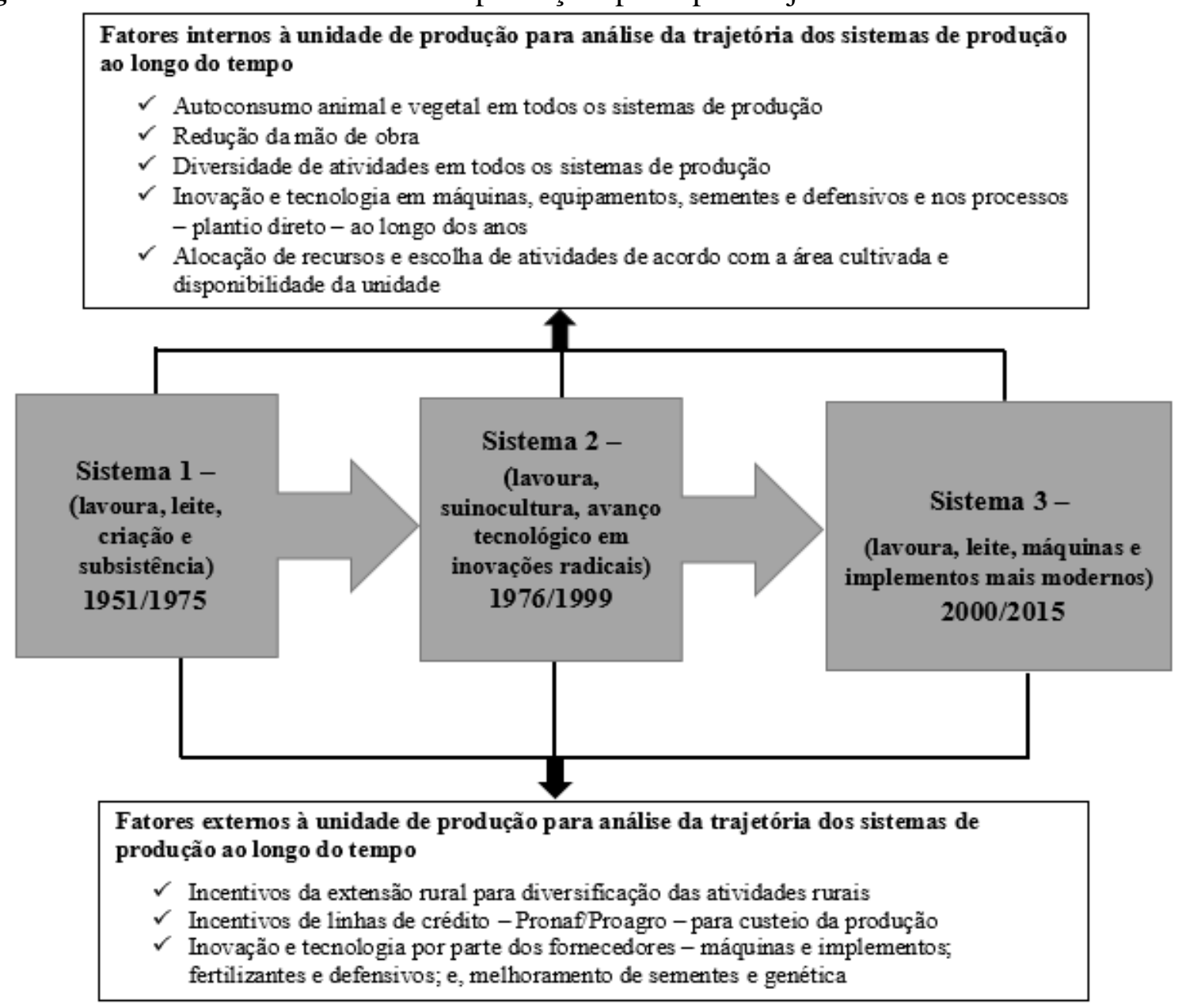

Fonte: Dados de Pesquisa, 2015. 
Os fatores internos que se destacam nesta análise dizem respeito ao autoconsumo animal e vegetal ter passado por todos os sistemas de produção, ocorrendo uma redução da mão de obra, além de que os sistemas apresentaram diversidade de atividades. As inovações incrementais se sobressaíram no último sistema por desenvolverem significativamente a unidade com a melhoria das tecnologias já existentes e, também por proporcionar qualidade de vida. Nos fatores externos, destaca-se a extensão rural que aprimorou o conhecimento dos produtores para diversificarem as atividades e para o aprimoramento das já desenvolvidas. As linhas de crédito do Pronaf e Proagro para o custeio da produção e as inovações e tecnologias por parte dos fornecedores são consideradas inovações adquiridas de fontes externas (instituições/empresas), conforme mostra a Figura 5.

\subsubsection{Síntese das principais inovações tecnológicas adotadas na UPA ao longo das trajetórias de cada sistema identificado}

$\mathrm{Na}$ análise do impacto das inovações tecnológicas nos processos produtivos da UPA ao longo das trajetórias de cada sistema identificado, verificou-se que, no final do Sistema de Produção 1 e a partir do Sistema de Produção 2, ocorreram investimentos maiores em inovações radicais, incrementais e menores em produtos e processos.

A seguir, no Quadro 5, estão as inovações em produtos e processos identificadas na UPA ao longo de sua trajetória.

Quadro 5: Inovação em produtos e processos identificadas na UPA

\begin{tabular}{|c|c|c|}
\hline Tipo de Inovação & $\begin{array}{l}\text { Inovação identificada/ano de } \\
\text { implementação }\end{array}$ & Resultados \\
\hline \multirow{3}{*}{ PRODUTOS } & Melhoramento da genética - 2000 & $\begin{array}{l}\text { Gado de corte de qualidade e novilhas com boa } \\
\text { genética para lactação. }\end{array}$ \\
\hline & Trigo e Aveia - 2000 & Diversificação e rotação das culturas. \\
\hline & $\begin{array}{l}\text { Soja transgênica - } 2003 \\
\text { Milho transgênico - } 2008\end{array}$ & $\begin{array}{l}\text { Qualidade do produto, aumento da produtividade, } \\
\text { menores custos com fertilizantes, herbicidas e } \\
\text { defensivos. }\end{array}$ \\
\hline \multirow{8}{*}{ PROCESSOS } & Trator -1955 & $\begin{array}{l}\text { Auxílio na grande maioria das atividades e na } \\
\text { utilização dos implementos. }\end{array}$ \\
\hline & Semeadeira - 1970 & $\begin{array}{l}\text { Plantio rápido, eficiente e com controle de sementes } \\
\text { plantadas. }\end{array}$ \\
\hline & $\begin{array}{l}\text { Uso de fertilizantes, herbicidas e } \\
\text { defensivos agrícolas }-1970\end{array}$ & $\begin{array}{l}\text { Diminuição das perdas e aumentar os ganhos de } \\
\text { produtividade. }\end{array}$ \\
\hline & Colheitadeira - 1975 & $\begin{array}{l}\text { Colheita rápida, eficiente e maiores ganhos } \\
\text { produtivos. }\end{array}$ \\
\hline & Pulverizador - 1970 & $\begin{array}{l}\text { Fácil manuseio, dosagem controlada e rápida } \\
\text { aplicação. }\end{array}$ \\
\hline & Plantio direto - 1995 & $\begin{array}{l}\text { Técnica de semeadura mais rápida do que a } \\
\text { convencional, com maiores rendimentos das culturas. }\end{array}$ \\
\hline & Ordenhadeira e resfriador - 2000 & $\begin{array}{l}\text { Aumento da produtividade do leite, fácil manuseio, } \\
\text { rapidez e armazenamento correto do produto. }\end{array}$ \\
\hline & Tanque de expansão - 2007 & $\begin{array}{l}\text { Capacidade maior de armazenamento, maior } \\
\text { qualidade. }\end{array}$ \\
\hline
\end{tabular}

Fonte: Dados de Pesquisa, 2015. 
a) Inovação de Produto - Ao longo dos anos, os produtores passaram a produzir de forma diferente, pois começaram a plantar soja e milho transgênicos, estimulados pelo possível aumento da produtividade, pela menor aplicação de defensivos e pelos gastos reduzidos com manejo e equipamentos.

b) Inovação de Processo - Os produtores passaram a utilizar, em 1995, o plantio direto, por considerarem esse método uma revolução em todas as regiões, já que auxiliou muito no manuseio, trazendo rapidez e eficiência no plantio. Em 2000, a introdução da ordenhadeira na produção leiteira permitiu ampliar a produção de leite para venda.

No sistema atual, os produtores passaram a introduzir uma estrutura organizacional modificada, apresentando mais controle sobre os custos e mantendo anotações relativas às atividades desenvolvidas, constituindo-se inovações organizacionais. Desse mesmo modo, no sistema atual, os produtores ampliaram os recursos tecnológicos da unidade - inovações incrementais - como máquinas, equipamentos e implementos agrícolas mais modernos, a fim de melhor produzir, em menos tempo e com melhores condições de trabalho.

Os produtores consideram importante a inovação e a tecnologia por parte dos fornecedores, inovações adquiridas de fontes externas, porque adquirem as tecnologias como máquinas mais tecnológicas que permitem uma produção eficaz, aumentando os números de produtividade. $\mathrm{O}$ mesmo ocorre com os insumos como os defensivos e fertilizantes agrícolas que agem rapidamente sobre as plantações. As rações para o gado leiteiro com mais proteínas possibilitam o aumento da produção de leite e a qualidade desse produto.

Os produtores consideram elevados os preços dos insumos melhorados e mais tecnológicos, afirmando que, "às vezes, é difícil "dar o giro", mas, muitas vezes, compensam pela maior produtividade e menores perdas de produção". Concordam ter adquirido patrimônios e ter tido bons retornos financeiros que cobriram os altos investimentos em inovações mecânicas e químicas, de forma que sempre se mantiveram sem dívidas. Reconhecem que os investimentos foram fundamentais para desenvolver as atividades e ter bons retornos financeiros (Dados da pesquisa, 2015).

Em 2007, os produtores, em parceria com a Pioneer Sementes, realizaram na unidade agrícola um dia de campo para experimentação de sementes de milho, soja, sorgo e herbicidas, o qual contou com a participação de integrantes, de fora do país, da empresa multinacional e dos agricultores da região. Percebe-se a difusão de tecnologias em conjunto com a extensão rural.

Quanto ao impacto das inovações para o sistema e aos impactos das inovações nas atividades agrícolas (produção de grãos e pecuária), conforme mostra o Quadro 4, os produtores os consideram impactos de alta importância. 
Quadro 4: Grau de importância das inovações para a UPA

\begin{tabular}{|c|c|c|}
\hline \multicolumn{2}{|r|}{ IMPACTOS } & IMPORTÂNCIA \\
\hline \multirow[b]{2}{*}{ Produto } & \multirow{2}{*}{$\begin{array}{l}\text { 1. Aumentou os tipos de produtos produzidos } \\
\text { 2. Melhorou a qualidade dos produtos } \\
\text { 3. Aumentou a produtividade }\end{array}$} & Média \\
\hline & & Alta \\
\hline \multirow[b]{2}{*}{ Mercado } & \multirow{2}{*}{$\begin{array}{l}\text { 1. Permitiu manter a sua participação no mercado } \\
\text { 2. Ampliou a sua participação no mercado ou permitiu abrir } \\
\text { novos mercados }\end{array}$} & Alta \\
\hline & & Média \\
\hline Renda & $\begin{array}{l}\text { 1. Aumentou a renda familiar } \\
\text { 2. Aumentou o valor da propriedade agrícola }\end{array}$ & Alta \\
\hline Qualidade de vida & 1. Melhorou a qualidade de vida ao desempenhar as tarefas & Alta \\
\hline Gestão & $\begin{array}{l}\text { 1. As inovações em produtos, processos etc., auxiliaram na } \\
\text { gestão da UPA }\end{array}$ & Alta \\
\hline Sucessão familiar & 1. Manteve os descendentes na unidade produtiva & Alta \\
\hline \multirow{4}{*}{ Produção de grãos } & 1. Aumentou a capacidade produtiva de grãos & \multirow{4}{*}{ Alta } \\
\hline & 2. Facilitou o desenvolvimento das atividades & \\
\hline & 3. Proporcionou o melhoramento da terra & \\
\hline & 4. Aumentou a qualidade de sementes & \\
\hline \multirow{3}{*}{ Pecuária } & 1. Aumentou a capacidade produtiva de leite & \multirow{3}{*}{ Alta } \\
\hline & 2. Facilitou o desenvolvimento das atividades & \\
\hline & 3. Aumentou a qualidade de genética & \\
\hline
\end{tabular}

Fonte: Dados de Pesquisa, 2015.

\section{CONSIDERAÇÕES FINAIS}

A análise dos processos históricos pelos quais a unidade de produção passou levou à compreensão e à definição dos três sistemas de produção identificados ao longo de sua trajetória. O estudo, contudo, buscou caracterizar, entender e analisar as evoluções passadas que levaram ao desencadeamento do sistema atual de produção, desenvolvido pelos produtores, frente às práticas de inovação em processos, produtos e formas de gestão.

Os fatores internos identificados que contribuíram para a evolução dos sistemas de produção implementados englobaram a apropriação de recursos locais, a ampliação da área, a implantação de recursos tecnológicos, como máquinas e implementos, sementes e defensivos agrícolas, a construção de infraestrutura, entre outros itens. E os fatores externos associaram decisões tomadas em nível regional e nacional, ligadas aos incentivos de crédito.

No Sistema de Produção 1, como percebeu-se, inicialmente, não havia investimentos em inovações, as atividades eram desenvolvidas de maneira convencional com equipamentos rudimentares, de modo que a maioria das culturas eram realizadas para subsistência na unidade e a produção de grãos era para comercialização. A partir de 1955 -1970, com a inserção de trator, colheitadeira e implementos, isto é, com a mecanização do processo produtivo, destacam-se as inovações radicais por processos, que geraram grandes mudanças nos processos assegurando, dessa forma, ganhos excepcionais, como Marx e Schumpeter trazem em suas afirmações.

Já, no Sistema de Produção 2, os produtores passaram a intensificar os investimentos de seus recursos, advindos dos cultivos dos grãos, em máquinas e implementos, a fim de mecanizar por completo as atividades, então, destacam-se algumas inovações radicais e outras inovações incrementais como, por exemplo, o aumento da frota de tratores, ou seja, 
investimentos nas tecnologias já existentes (SAENZ E GARCÍA CAPOTE, 2002). Nesse sistema, nota-se que os produtores passaram a ter mais instrução sobre as atividades, ou seja, inovação adquirida de fontes externas, auxiliando no uso de máquinas, defensivos nas plantações e, ainda, o plantio direto em 1995, que revolucionou a agricultura, constituindo-se inovação tecnológica de processo.

No Sistema de Produção 3, as inovações e tecnologias foram bem significativas para o aumento da produção na unidade, que, na grande maioria, podem ser consideradas inovações incrementais, assim como a renovação da maquinaria e de implementos. Destaca-se a inovação radical por processos - com a intensificação do plantio direto em todas as áreas, variedade e tecnologia em defensivos e fertilizantes agrícolas, aquisição de máquinas e implementos mais modernos e infraestrutura melhorada. A inovação de produto apresenta-se na incorporação de sementes transgênicas, novas culturas e a tecnologia de gestão está presente na profissionalização do setor, acrescido de controle e planejamento.

Os resultados do estudo comprovam os argumentos teóricos, que o significativo crescimento da produtividade das culturas agrícolas e a inserção em novas atividades devemse, neste caso, aos avanços tecnológicos ocorridos no setor agrícola. Fatores como o uso de bioquímicos (inseticidas, fungicidas, fertilizantes) e mecânicos (máquinas e equipamentos agrícolas) corroboram essa hipótese na UPA investigada.

Igualmente importante, foi o acesso a políticas públicas como, por exemplo, políticas de crédito (Pronaf e Proagro) com o qual os produtores conseguiram adiantar gastos com insumos e antecipar os lucros, para pagar os empréstimos e prosseguir o próximo ciclo de produção. Assim, como a extensão rural, no compromisso de instruir e proporcionar conhecimentos em torno das novas tecnologias aos produtores, exercendo papel fundamental na difusão tecnológica, como afirma Oslo (2013, p.15) "a difusão de novas tecnologias são essenciais para o crescimento da produção e o aumento da produtividade". Nesse sentido, é pertinente destacar também, o papel importante das pesquisas agropecuárias via Embrapa, no desenvolvimento de novas inovações tecnológicas para o setor.

Em linhas gerais os impactos das inovações para o sistema produtivo, identificados por meio dos produtores, foram o melhoramento da qualidade dos produtos, o aumento da produtividade, a manutenção no mercado, o aumento da renda familiar, o aumento do valor da propriedade agrícola e o melhoramento da qualidade de vida ao desempenhar as tarefas. Além disso, as inovações em produtos e processos auxiliaram na gestão com maior planejamento e mais bem profissionalizada da UPA e, também, na permanência dos descendentes na unidade.

Por fim, este trabalho é um passo inicial na busca por uma análise das trajetórias de UPA pela óptica da inovação dos processos tecnológicos da agricultura em uma unidade de produção agrícola. Constituiu-se em um estudo de caso único e não pode representar uma região ou mesmo a realidade de um município, por isso mostra-se limitado a esse alcance metodológico. Entretanto, seu objetivo maior foi justamente a construção de um modelo que possa ser aplicado de forma mais ampla, o que poderá se concretizar em novos estudos. 


\section{REFERÊNCIAS}

ALBUQUERQUE, Marcos Cintra Cavalcanti de; NICOL, Robert. Economia agrícola: o setor primário e a evolução da economia brasileira. São Paulo: McGraw Hill, 1987.

BNDES. PAISS agrícola. Disponível em:

<http://www.bndes.gov.br/SiteBNDES/bndes/bndes_pt/Areas_de_Atuacao/Inovacao/paissagr icola.html>. Acesso em: 09 out. 2015.

DEFUMIER. Les projets de développement agricole: Manuel d'expertise. Éditions KARTHALA, Paris, 1996.

FRANTZ, Telmo Rudi. Inovação tecnológica e desenvolvimento: noções introdutórias e perspectivas analíticas à luz das teorias econômicas. In: SIEDENBERG, Dieter Rugard. Desenvolvimento sob múltiplos olhares. Ijuí: Unijuí, 2012.

FRITZ FILHO, Luiz Fernando. Análise das trajetórias das unidades de produção agrícolas do município de Passo Fundo/RS. Tese (Doutorado em Desenvolvimento Rural) Universidade Federal do Rio Grande do Sul, Faculdade de Ciências Econômicas, Programa de Pós-Graduação em Desenvolvimento Rural, Porto Alegre, 2009.

FÜRSTENAU, Vivian; Fundação de Economia e Estatística Siegfried Emanuel Heuser. O crédito rural no Brasil e seus efeitos sobre a agricultura gaúcha: 1965-84. Porto Alegre: FEE, 1988.

KALKMANN, Márcio Leandro. A incorporação tecnológica na agricultura familiar. [artigo científico]. 2013. Disponível em:

<http://www.fahor.com.br/publicacoes/jopec/2013/A_Incorporacao_.pdf >. Acesso em: 20 ago. 2015.

OSLO. Manual de Oslo: diretrizes para coleta e interpretação de dados sobre inovação. 3. ed. Campinas: Finep, 2013. Disponível em:

<http://download.finep.gov.br/imprensa/manual_de_oslo.pdf >. Acesso em: 02 set. 2015.

MIGUEL, L.de A. Dinâmica e diferenciação de sistemas agrários. Coordenado pelo Curso de Graduação Tecnológica - Planejamento e Gestão para o Desenvolvimento Rural da SEAD/UFRGS. - Porto Alegre: Editora da Ufrgs, 2009.

MINISTÉRIO DO DESENVOLVIMENTO AGRÁRIO. Mais alimentos. Disponível em: <http://www.mda.gov.br/sitemda/secretaria/saf-mais/sobre-o-programa>. Acesso em: 21 mai. 2015.

RÜCKERT, A.A. Metamorfoses do Território a agricultura de trigo/soja no planalto médio rio-grandense 1930-1990. Porto Alegre: UFRGS EDITORA, 2003.

SAENZ, Tirso W.; GARCÍA CAPOTE, Emílio. Ciência, inovação e gestão tecnológica. Brasília: CNI/IEL/SENAI, ABIPTI, 2002.

SALUME, Jamilli Almeida; SILVA, Elaine Cristina Gomes; CHRISTO, Bruno Fardim. Elementos de administração rural avaliados em pequenas propriedades rurais de Alegre - ES.

Caderno Profissional de Administração: Unimep, v. 5, n. 1, 2015. 
SANTOS, Luiz Antonio Casemiro dos; SANCHEZ, Gabriela Fernandez. Pinagro - Proposta de pesquisa de inovação na agricultura. [artigo científico]. Goiânia, 2014.

SCHUMPETER, Josep Alois. Teoria do desenvolvimento econômico: uma investigação sobre lucros, capital, crédito, juro e o ciclo econômico. 3. ed. São Paulo: Nova Cultural, 1988.

SILVA NETO, B. et al. Sistemas Agrários do Rio Grande do Sul. Análise e recomendações de Políticas. Ijuí: Unijuí, 2005.

SOUZA, Nali de Jesus de. Desenvolvimento econômico. 5. ed. São Paulo: Atlas, 2007.

VIEIRA FILHO, José Eustáquio Ribeiro. Transformação histórica e padrões tecnológicos da agricultura brasileira. In: BUAINAIN, Antônio Márcio; et al. (Ed.). O mundo rural no Brasil do século 21: a formação de um novo padrão agrário e agrícola. p. 395 - 452. Brasília, DF: Embrapa, 2014.

. Políticas públicas de inovação no setor agropecuário: uma avaliação dos fundos setoriais. Rio de Janeiro. mar. 2012. Disponível em:

<http://ipea.gov.br/agencia/images/stories/PDFs/TDs/td_1722.pdf>. Acesso em: 9 out. 2015.

YIN, Robert K. Estudo de caso: planejamento e métodos. 4. ed. Porto Alegre: Bookman, 2010. 